DOI 10. 18307/2017. 0602

(c) 2017 by Journal of Lake Sciences

\title{
太湖流域上游平原河网区水质空间差异与季节变化特征
}

\author{
张 涛 ${ }^{1,2}$, 陈求稳 ${ }^{1 * *}$, 易齐涛 ${ }^{1}$, 王 敏 ${ }^{1}$, 黄 蔚 ${ }^{1}$, 冯然然 ${ }^{1}$ \\ ( 1 : 南京水利科学研究院生态环境研究中心, 南京 210029) \\ (2: 太湖流域管理局水利发展研究中心, 上海 200434)
}

\begin{abstract}
摘 要: 在太湖流域上游的宜溧一洮滆水系主要河道设置 67 个监测点, 分别于 2014 年 1 月 (冬季)、 4 月 (春季)、 8 月 (夏 季)、11月(秋季) 进行水质监测, 采用多元统计方法分析了水质的空间差异性和季节性变化, 并利用水质标识指数法对 水环境质量进行评价. 结果表明, 宜溧一洮滆水系污染程度较严重, 总氮 $(\mathrm{TN})$ 、总磷 $(\mathrm{TP})$ 和高镇酸盐指数 $\left(\mathrm{COD}_{\mathrm{Mn}}\right)$ 浓度 年均值分别为 $4.93 、 0.26$ 和 $7.63 \mathrm{mg} / \mathrm{L}$; 单因素多元方差分析和聚类分析显示污染物浓度具有显著时空差异性, 时间上冬、 春季污染程度较高而夏、秋季较低, 空间上无锡和常州氮、磷污染较为严重, 宜兴和溧阳市有机污染程度较高; 水质标识 评价结果显示流域内水质基本为 $\mathrm{IV}$ 类或 $\mathrm{V}$ 类,其中 $\mathrm{TN} 、 \mathrm{TP}$ 及 $\mathrm{COD}_{\mathrm{Mn}}$ 是关键污染指标.
\end{abstract}

关键词: 太湖流域; 宜溧一洮滆水系; 多元统计分析; 水质评价; 水质标识指数法

\section{Spatial and seasonal variations of water quality in the upstream plain river networks of the Taihu Basin}

\author{
ZHANG Tao ${ }^{1,2}$, CHEN Qiuwen ${ }^{1 * *}$, YI Qitao ${ }^{1}$, WANG Min ${ }^{1}$, HUANG Wei ${ }^{1}$ \& FENG Ranran ${ }^{1}$ \\ (1: Center for Eco-Environmental Research, Nanjing Hydraulic Research Institute, Nanjing 210029, P.R.China) \\ (2: Water Conservancy Development Research Center, Taihu Basin Authority, Shanghai 200434, P.R.China)
}

\begin{abstract}
Sixty-seven water sampling sites in the Yili-Taoge plain river networks of the upstream area of the Taihu Basin were set to characterize its water quality with spatiotemporal distribution. Water sampling trips were conducted in January (winter), April (spring), August (summer), November ( autumn) of 2014, and main water quality parameters were concentrated on nutrients and organic matters. Spatial and seasonal variations of water quality were analyzed by using the multivariate statistical methods and water quality were assessed by employing the comprehensive water quality identification index. The results indicated that pollution degree in the research area was severe. The averaged concentrations of total nitrogen ( TN), total phosphorus ( TP) and permanganate index $\left(\mathrm{COD}_{\mathrm{Mn}}\right)$ were $4.93 \mathrm{mg} / \mathrm{L}, 0.26 \mathrm{mg} / \mathrm{L}$ and $7.63 \mathrm{mg} / \mathrm{L}$, respectively. One-way multivariate analysis and cluster analysis showed significantly spatiotemporal patterns of pollutants. Pollution levels in winter and spring were higher than that in summer and autumn. Pollution of nitrogen and phosphorus were heavier in the Wuxi and Changzhou areas, whereas organic matter pollution was more serious in the Yixing and Liyang areas. Water quality in the upstream plain river networks can meet the criteria of Grade IV or V of National Standards for Surface Water Quality, characterized by pollution of TN, TP and $\mathrm{COD}_{\mathrm{Mn}}$.

Keywords: Taihu Basin; Yili-Taoge water system; multivariate statistical analysis; water quality assessment; water quality identification index
\end{abstract}

近几十年来，随着我国工农业和城市化的快速发展，强烈的人类活动导致湖泊内营养盐不断富集 ${ }^{[1]}$, 富营养化程度加剧 ${ }^{[2]}$, 有研究表明我国 $85 \%$ 以上的湖泊处于富营养化的水平 ${ }^{[3]}$. 湖泊富营养化及由此引起 的蓝藻水华已严重影响湖泊的生态功能与饮水安全 ${ }^{[4]}$, 成为制约经济和社会持续发展的重要因素. 我国过

* 国家自然科学基金项目 $(51579149,51609142,51609144)$ 和江苏省水利厅水利科技重大项目 $(2015005,2016021$, 2016030) 联合资助. 2016-11-11 收稿; 2017-01-24 收修改稿. 张涛 (1993 ), 女, 硕士研究生; E-mail: zt7914375@163.com.

** 通信作者; E-mail:qwchen@ nhri.cn. 
去二十多年中针对富营养化严重的大型湖泊开展了一系列的整治措施 ${ }^{[2]}$, 部分重点湖泊水质有所改善, 但 水环境状况总体恶化的趋势尚未得到根本遏制 ${ }^{[5]}$. 湖泊富营养化治理主要在于外源控制和内源削减, 其中 外源控制是根本. 因此解析外源营养物质来源, 有效降低外部营养物质的输人, 实现流域水系水质目标管理 是当前湖泊富营养化治理的首要任务 ${ }^{[6-7]}$. 人湖河流是营养物质输运人湖的关键路径, 其水质对湖泊水环境 状况有着重要而直接的影响, 因此研究人湖河流水质的变化规律, 控制人湖河流污染物浓度, 对改善湖泊水 体富营养化状况具有重要意义 ${ }^{[8]}$.

目前, 针对脉络较为清晰且结构相对简单的树状河流的水质时空变化特征研究比较多 ${ }^{[9-13]}$; 太湖流域是 我国典型的平原河网区, 流域城镇化、工业化程度高, 污染负荷严重, 河网水文水动力条件及负荷来源复杂, 河流水质影响因素众多 ${ }^{[14-15]}$. 此前人湖河流水质监测与分析主要集中于环湖河口及周边区域 ${ }^{[16-17]}$, 缺乏人 湖河网多断面、大尺度的水质时空分布研究. 本研究选取太湖上游流域中的宜溧一洮滆水系作为对象, 优化 设置高密度的水质监测网点, 对河流水质指标进行测定, 并采用水质标识指数法评价河流水质状况, 旨在揭 示典型平原河网水质空间差异和季节变化特征, 以期为太湖流域人湖河流水质目标管理及污染负荷控制提 供相关依据.

\section{1 研究区域与方法}

\section{1 研究区概况与样点布设}

宜溧一洮滆水系主要由宜溧河水系和洮滆水系两部分组成. 宜溧河水系也称南河水系, 发源于茅山山区 和苏浙皖三省交界处的丘陵山地 ${ }^{[18]}$, 途径无锡宜兴市、溧阳市, 土地利用类型以耕地为主, 干流长 $50 \mathrm{~km}$, 下 游北与洮滆水系相连, 宜溧河水系人湖水量约占太湖上游来水总量的 $25 \%$. 洮滆水系是由山区河道和平原 河道组成的河网,集镇江、丹阳、金坛一带的丘陵岗坡径流, 经洮湖、滆湖调蓄后由常州太滆运河、漕桥河、殷 村港等河流汇人太湖 ${ }^{[19]}$, 同时又以丹金溧漕河、扁担河、武宜运河等多条南北向河道与沿江水系相通形成东 西逢源、南北交汇的网络状水系. 洮滆水系人湖水量约占太湖上游来水总量的 $20 \%$ 左右 ${ }^{[20]}$.

在宜溧一洮滆水系共布设 67 个水质监测站点 (图 1). 监测点布设覆盖主要 4 级以上河道, 并充分考虑 水系交汇结构. 其中宜溧水系共布设 25 个采样点, 分布在大浦港 ( Y1、Y2)、东氿 ( Y3 )、西氿 ( Y4 ) 、北溪河 ( Y5、Y19、Y20、Y22)、溧宜河 ( Y6 Y Y1)、埝径河 ( Y13、Y16)、桃溪 (Y12、Y14、Y15)、戴溧河 ( Y17)、赵村河 (Y18)、丹金溧漕河 ( Y 21)、淳溧河 (Y23)、中河 (Y24) 和南河 $(Y 25)$. 洮滆水系共布设 42 个采样点, 分布在

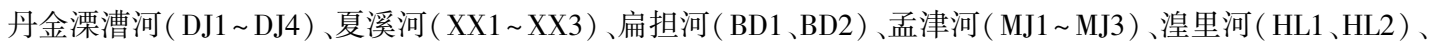
北干河 (BG1、BG2)、中干河 (ZG1、ZG2)、北河( BH1、BH2)、武宜漕河 (WY1～WY4)、漕桥河 (CQ1、CQ2)、太 滆运河 ( TG1 TG4)、殷村港 (YC1、YC2)、烧香河 (SX1、SX2)、横塘河 (HT1)、锡溧漕河 (XL1～XL4) 和直湖 港 ( ZH1 ZH3).

\section{2 样品采集与分析}

样品采集按春、夏、秋、冬 4 个季节进行, 于 2014 年 $1 、 4 、 8 、 11$ 月完成. 水温、 $\mathrm{DO}$ 及 $\mathrm{pH}$ 用水质多参数仪 现场测定; 实验室分析的指标包括总氮 $(\mathrm{TN})$ 、硝态氮 $\left(\mathrm{NO}_{3}^{-}-\mathrm{N}\right)$ 、亚硝态氮 $\left(\mathrm{NO}_{2}^{-}-\mathrm{N}\right)$ 、氨氮 $\left(\mathrm{NH}_{3}-\mathrm{N}\right)$ 、总磷 $(\mathrm{TP}) 、$ 正磷酸盐 $\left(\mathrm{PO}_{4}^{3-}-\mathrm{P}\right)$ 、高锰酸盐指数 $\left(\mathrm{COD}_{\mathrm{Mn}}\right)$ 、碱度 $(\mathrm{ALK})$ 、总悬浮物 $(\mathrm{TSS})$ 等, 共计 12 项. 水样的收 集、保存、运输及分析方法依据《水和废水监测分析方法》(第 4 版) 进行 ${ }^{[21]}$.

\section{3 水质时空变异分析与评价}

1.3.1 时空变异分析 在水质评价过程中, 考虑到水质在时间、空间上的差异性及相似性, 采用方差分析 (ANOVA) 的方法对各评价指标分别进行季节间和空间上的显著差异性检验, 以判断各检测指标在不同断 面以及不同季节间是否存在显著差异 ${ }^{[22]}$. 方差分析由 Fisher 等提出, 用于两个及以上样本均数差别的显著 性检验, 其基本原理是将全部观测数据的总变异分解为组间变异和组内变异, 如果组间变异远远大于组内 变异, 则认为控制因素对因变量产生了影响 ${ }^{[23]}$. 本研究的控制变量分别为时间和空间, 属于单因素多元 ANOVA, 显著性检验公式为:

$$
\lambda^{2} / n=\frac{|W|}{|B+W|} \sim \Lambda(p, n-m, m-1)
$$




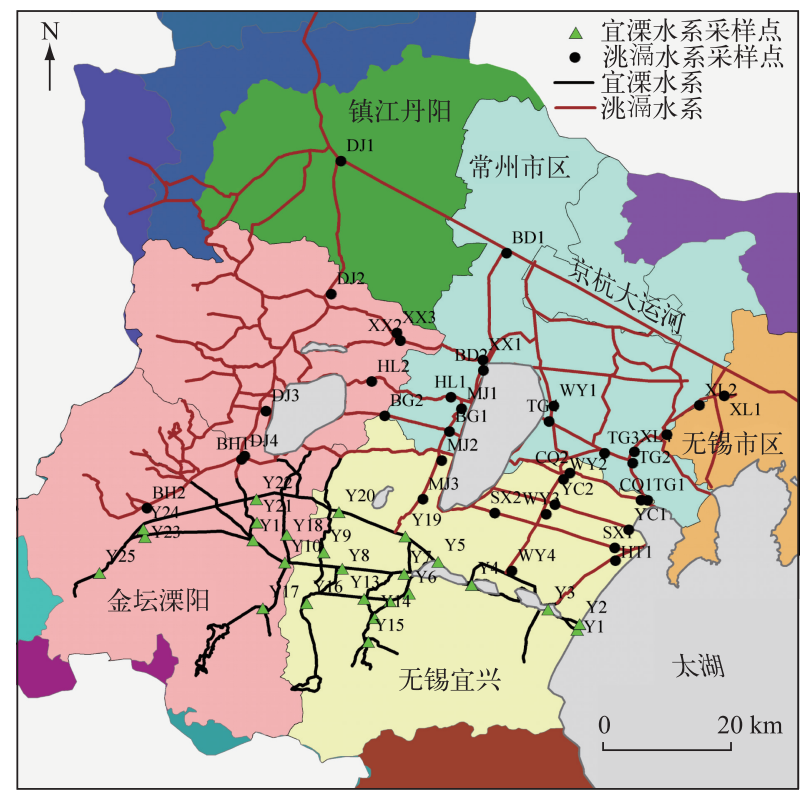

图 1 宜溧一洮滆水系水质监测点分布

Fig.1 The distribution of water sampling sites in the Yili-Taoge river networks

式中, $n$ 为样本数; $B$ 为组间离差平方和矩阵; $W$ 为组内离差平方和矩阵; $p$ 为向量维数; $m$ 为水平数. $\Lambda$ 统计 量服从自由度为 $(p, n-m, m-1)$ 的 $\Lambda$ 分布, 当 $\lambda^{2} / n$ 值大于显著水平 $\alpha$ 时, 则表明在该控制变量下不同水平 各总体均值不存在显著性差异, 反之,则存在显著性差异.

1.3.2 空间层次聚类分析 聚类分析是根据某些数量特征将观察对象进行分类的一种统计方法, 其实质是根 据样品或变量之间的亲疏程度, 通过逐次聚合, 将性质最接近的对象结合在一起聚成一类 ${ }^{[11]}$. 在水质评价 中, 考虑到水质在时间、空间上的差异性及相似性, 本研究采取应用较为广泛的层次聚类分析, 亲疏程度的 计算包括两类: 样本间距离和组间距离, 其中计算样本间距离采用欧氏距离平方和法, 即两点间实际距离的 平方和; 计算组间距离采用离差平方和法, 又称 Ward 法, 其基本思想是以平方欧氏距离为标准, 先将集合中 每个样本自成一类, 计算类重心间方差, 将离差平方和增加幅度最小的两类进行合并, 每次通过合并减少一 类, 此时离差平方和出现并逐步增大, 选择使离差平方和增加最小的两类合, 随后依次将所有类别逐级合 并 ${ }^{[24]}$. 聚类分析选取的水质指标包括耗氧污染物类 ( $\mathrm{DO} 、 \mathrm{COD}_{\mathrm{Mn}}$ 及 $\left.\mathrm{NH}_{3}-\mathrm{N}\right)$ 和营养盐类 ( $\mathrm{TN}$ 及 $\mathrm{TP}$ ). 时空变 异分析和空间层次聚类分析均使用 SPSS 19.0 软件完成.

1.3.3 综合水质评价 宜溧一洮滆水系多为渔业、工业及农业用水, 其水功能区目标以 III类或 IV 类为主, 水质 评价采用综合水质标识指数法 $\left(I_{\mathrm{wq}}\right)^{[25]}$, 标识指数由整数位和 3 位或 4 位小数位组成, 其结构为:

$$
I_{\mathrm{wq}}=X_{1} \cdot X_{2} X_{3} X_{4}
$$

式中, $X_{1} . X_{2}$ 由计算获得, $X_{3}$ 和 $X_{4}$ 根据比较结果得到. 其中, $X_{1}$ 为河流总体的综合水质类别; $X_{2}$ 为综合水质在 $X_{1}$ 类水质变化区间内所处位置, 从而实现在同类水中进行水质优劣比较; $X_{3}$ 为参与综合水质评价的水质指 标中, 劣于水环境功能区目标的单项指标个数; $X_{4}$ 为综合水质类别与水体功能区类别的比较结果, 视综合水 质的污染程度,一位或两位有效数字.

$$
X_{1} \cdot X_{2}=\frac{1}{m} \sum\left(P_{1}+P_{2}+\cdots+P_{m}\right)
$$

式中, $m$ 为参加综合水质评价的水质单项指标的数目; $P_{1} 、 P_{2} 、 P_{m}$ 分别为第 $1 、 2 、 m$ 个水质因子的单因子水质 指数, 为对应单因子水质标识指数中的整数位和小数点后第 1 位 (单因子水质标识指数中的 $X_{1} \cdot X_{2}$ ).

通过综合水质标识指数 $X_{1} . X_{2}$, 结合《国家地表水环境质量标准》的分类, 可以判断水体的水质类别和污 
染程度: 当 $1.0 \leqslant X_{1} . X_{2} \leqslant 2.0$ 时, 水质状况为 $\mathrm{I}$ 类; 当 $2.0<X_{1} . X_{2} \leqslant 3.0$ 时, 水质状况为 II 类; 当 $3.0<X_{1} . X_{2} \leqslant 4.0$ 时, 水质状况为 III类; 当 $4.0<X_{1} . X_{2} \leqslant 5.0$ 时, 水质状况为 $\mathrm{IV}$ 类; 当 $5.0<X_{1} . X_{2} \leqslant 6.0$ 时, 水质状况为 $\mathrm{V}$ 类; 当 $6.0<$ $X_{1} \cdot X_{2} \leqslant 7.0$ 时,水质状况为劣 $\mathrm{V}$ 类但不黑臭; 当 $X_{1} \cdot X_{2}>7.0$ 时,水质状况为劣 $\mathrm{V}$ 类且黑臭.

\section{2 结果与分析}

\section{1 流域水质时空分布特征}

宜溧一洮滆水系水质总体呈弱碱性, DO 浓度季节均值范围为 $3.75 \sim 6.51 \mathrm{mg} / \mathrm{L}$, 部分监测点浓度低于 IV 类水质标准 $(3.0 \mathrm{mg} / \mathrm{L}) . \mathrm{COD}_{\mathrm{Mn}}$ 和 TP 浓度季节均值范围分别为 $5.98 \sim 8.78$ 和 $0.22 \sim 0.31 \mathrm{mg} / \mathrm{L}$ (表 1 ), 均属 于 IV 类水, $\mathrm{TN}$ 浓度季节均值范围为 $3.23 \sim 6.89 \mathrm{mg} / \mathrm{L}$, 远高于 $\mathrm{V}$ 类水质标准.

表 1 宜溧一洮滆水系监测站点水质指标季节均值统计

Tab.1 Mean values of water quality parameters in the Yili-Taoge river networks

\begin{tabular}{|c|c|c|c|c|c|c|c|c|c|c|c|}
\hline \multirow{2}{*}{ 季节 } & \multirow{2}{*}{ 统计值 } & \multirow{2}{*}{$\begin{array}{c}\text { 温度/ } \\
{ }^{\circ} \mathrm{C}\end{array}$} & \multirow{2}{*}{$\mathrm{pH}$} & \multicolumn{8}{|c|}{ 水质指标浓度/ $(\mathrm{mg} / \mathrm{L})$} \\
\hline & & & & DO & $\mathrm{COD}_{\mathrm{Mn}}$ & $\mathrm{TP}$ & $\mathrm{PO}_{4}^{3-}-\mathrm{P}$ & $\mathrm{TN}$ & $\mathrm{NH}_{3}-\mathrm{N}$ & $\mathrm{NO}_{2}^{-}-\mathrm{N}$ & $\mathrm{NO}_{3}^{-}-\mathrm{N}$ \\
\hline \multirow[t]{4}{*}{ 春季 } & 最小值 & 16.30 & 7.01 & 3.00 & 5.60 & 0.06 & 0 & 1.60 & 0.01 & 0.03 & 0.60 \\
\hline & 最大值 & 20.00 & 8.00 & 10.60 & 9.30 & 0.61 & 0.08 & 9.40 & 2.42 & 0.76 & 6.30 \\
\hline & 均值 & 18.34 & 7.54 & 6.51 & 7.01 & 0.25 & 0.01 & 5.20 & 0.78 & 0.19 & 2.39 \\
\hline & 标准差 & 0.66 & 0.21 & 1.66 & 0.87 & 0.11 & 0.02 & 1.57 & 0.62 & 0.13 & 1.02 \\
\hline \multirow[t]{4}{*}{ 夏季 } & 最小值 & 26.20 & 6.59 & 1.30 & 4.10 & 0.10 & 0 & 1.40 & 0 & 0 & 0.10 \\
\hline & 最大值 & 32.80 & 7.75 & 7.00 & 21.60 & 0.61 & 0.24 & 6.20 & 1.81 & 0.79 & 2.70 \\
\hline & 均值 & 28.76 & 7.48 & 3.75 & 8.71 & 0.22 & 0.02 & 3.23 & 0.18 & 0.23 & 1.14 \\
\hline & 标准差 & 1.54 & 0.17 & 1.08 & 3.28 & 0.10 & 0.03 & 0.81 & 0.28 & 0.20 & 0.57 \\
\hline \multirow[t]{4}{*}{ 秋季 } & 最小值 & 13.40 & 7.15 & 2.10 & 3.30 & 0.05 & 0 & 1.70 & 0 & 0 & 0.20 \\
\hline & 最大值 & 17.80 & 8.75 & 12.00 & 12.20 & 0.66 & 0.04 & 8.70 & 0.95 & 0.71 & 6.50 \\
\hline & 均值 & 15.34 & 7.66 & 6.16 & 5.98 & 0.26 & 0.01 & 4.42 & 0.14 & 0.16 & 1.76 \\
\hline & 标准差 & 0.99 & 0.27 & 1.62 & 1.72 & 0.14 & 0.01 & 1.44 & 0.19 & 0.17 & 0.95 \\
\hline \multirow[t]{4}{*}{ 冬季 } & 最小值 & 5.30 & 6.95 & 3.50 & 5.00 & 0.07 & 0 & 3.05 & 0.36 & 0.01 & 0.99 \\
\hline & 最大值 & 10.90 & 8.56 & 10.00 & 15.40 & 0.70 & 0.25 & 11.30 & 1.88 & 0.29 & 4.70 \\
\hline & 均值 & 7.81 & 7.65 & 6.43 & 8.78 & 0.31 & 0.04 & 6.89 & 1.16 & 0.11 & 2.90 \\
\hline & 标准差 & 1.19 & 0.27 & 1.39 & 2.30 & 0.14 & 0.04 & 1.94 & 0.35 & 0.07 & 0.91 \\
\hline
\end{tabular}

2.1.1 $\mathrm{COD}_{\mathrm{Mn}}$ 的时空分布特征 各监测点 $\mathrm{COD}_{\mathrm{Mn}}$ 浓度总体呈现出夏、冬季较高, 春秋季较低的特征 (图 2). 春 季变化范围为 $5.60 \sim 9.30 \mathrm{mg} / \mathrm{L}$, 平均为 $7.01 \mathrm{mg} / \mathrm{L}$. 秋季 $\mathrm{COD}_{\mathrm{Mn}}$ 浓度为全年最低, 其变化区间在 $3.30 \sim 12.20$ $\mathrm{mg} / \mathrm{L}$ 之间, 均值为 $5.98 \mathrm{mg} / \mathrm{L}$. 夏季 $\mathrm{COD}_{\mathrm{Mn}}$ 变化范围为 $4.10 \sim 21.60 \mathrm{mg} / \mathrm{L}$ 之间, 平均为 $8.71 \mathrm{mg} / \mathrm{L}$. 冬季 $\mathrm{COD}_{\mathrm{Mn}}$ 变化范围为 $5.00 \sim 15.40 \mathrm{mg} / \mathrm{L}$, 平均为 $8.78 \mathrm{mg} / \mathrm{L}$, 与夏季相差甚微. 流域空间上也存在一定的变异性. 整体来看城镇区域周围 $\mathrm{COD}_{\mathrm{Mn}}$ 农度明显高于流域上游和以农业活动为主的区域, 在城镇集中、工业发达的 锡溧漕河一武宜运河、扁担一孟津河、溧宜河及环太湖河口一线浓度较高, 而农业为主的区域洮湖及滆湖周 围浓度相对较低.

2.1.2 TN 和 DIN 的时空分布特征 宜溧一洮滆水系 TN 浓度季节变化规律明显, 其大小顺序为冬季>春季> 夏秋季. 各监测站点 $\mathrm{TN}$ 浓度春季变化范围为 $1.60 \sim 9.40 \mathrm{mg} / \mathrm{L}$, 平均为 $5.20 \mathrm{mg} / \mathrm{L}($ 表 1). 夏、秋季流域内大 部分监测点浓度均较低, 其中夏季 TN 浓度变化范围为 $1.40 \sim 6.20 \mathrm{mg} / \mathrm{L}$, 均值为 $3.23 \mathrm{mg} / \mathrm{L}$; 秋季 TN 浓度略 有升高, 平均为 $4.42 \mathrm{mg} / \mathrm{L}$. 冬季 TN 浓度显著增加, 最大值高达 $11.30 \mathrm{mg} / \mathrm{L}$, 平均为 $6.89 \mathrm{mg} / \mathrm{L}$. TN 浓度的空 间变异性较大且呈现明显的分布规律 (图 2). 从流域上游向下游流动的过程中 TN 浓度逐渐升高, 同时在城 镇、工业化集中的区域如京杭运河、锡溧漕河一武宜运河、扁担一孟津河、夏溪河等浓度较高,浓度最高的河 流集中于常州的武进区周围的水系.

宜溧一洮滆水系各监测点溶解无机氮 (DIN) 为 TN 的主要组成成分, 4 个季节均值比例范围为 $45.85 \%$ 


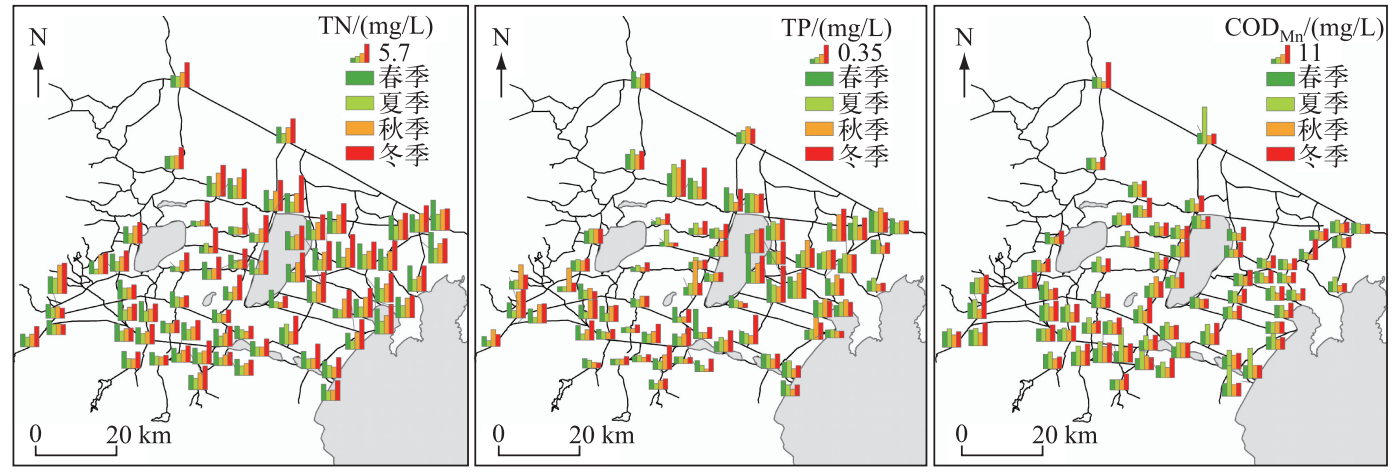

图 2 宜溧一洮滆水系污染物浓度的时空分布

Fig.2 The spatio-temporal distributions of pollutant concentration in the Yili-Taoge river networks

$66.91 \%$, 其中春季均值比例最高, 秋季最低. 不同季节 3 种 $\left(\mathrm{NO}_{3}^{-}-\mathrm{N} 、 \mathrm{NO}_{2}^{-}-\mathrm{N} 、 \mathrm{NH}_{3}-\mathrm{N}\right)$ 形态氮所占比例具有一 定的差异 (图 3), 其中 $\mathrm{NO}_{3}^{-}-\mathrm{N}$ 为主要存在形态, 4 个季节监测期间其占无机氮比例范围为 $68.59 \% \sim 82.96 \%$. $\mathrm{NH}_{3}-\mathrm{N}$ 在 DIN 中所占的比例具有强烈的季节分布规律, 冬季和春季污染较为严重, 平均比例分别为 $28.82 \%$ 和 $21.22 \%$,夏季和秋季污染较小, 平均比例分别为 $15.04 \%$ 和 $8.56 \%$. 此外, 在空间上也呈现较强的规律性, 同 TN 一样, 春季锡溧漕河一武宜运河、扁担一孟津河、夏溪河等河流的 $\mathrm{NH}_{3}-\mathrm{N}$ 浓度较高, 在 DIN 中所占比 例也较大,浓度最高的区域也集中于常州武进区周围的水系; 冬季整个流域 $\mathrm{NH}_{3}-\mathrm{N}$ 污染均较为严重; 夏、秋 季 $\mathrm{NH}_{3}-\mathrm{N}$ 污染主要集中在少数监测点,其中夏溪河、孟津河污染较为严重.

2.1.3 TP 的时空分布特征 宜溧一洮滆水系 TP 浓度季节变化主要表现为冬季最大, 秋、春季次之,夏季最小 (图 2). 其中, 夏季 TP 浓度范围为 $0.10 \sim 0.61 \mathrm{mg} / \mathrm{L}$, 均值 $0.22 \mathrm{mg} / \mathrm{L}$; 冬季浓度范围为 $0.07 \sim 0.70 \mathrm{mg} / \mathrm{L}$, 均值 为 $0.31 \mathrm{mg} / \mathrm{L}$ (表 1). 空间上主要是运河明显高于其他区域, 与 $\mathrm{TN}$ 一样, 污染最为严重区域集中于武进区周 边水系, 如锡溧漕河一武宜运河、扁担一孟津河和夏溪河等河流, 流域下游区域河流要高于上游区域河流.

\section{2 数据时空尺度多元方差分析}

监测数据时空多元方差分析结果如表 2、表 3 所示. 4 种不同统计量中 Pillai's Trace、Hotelling-Lawley 及 Roy's Greatest Root 统计值越大, 表明变量对结果的影响越大, 而 Wilks' Lambda 统计量则相反. 以时间多元方差

表 2 采样点时间多元方差分析*

Tab.2 Temporal variations of sampling sites based on One-way multivariate analysis

\begin{tabular}{lcccccc}
\hline 统计量 & Value & F Value & Num DF & Den DF & Sig. & Partial Eta sq. \\
\hline Pillai's Trace & 1.130 & 31.686 & 15 & 786.000 & 0 & 0.377 \\
Wilks' Lambda & 0.185 & 40.268 & 15 & 718.147 & 0 & 0.430 \\
Hotelling-Lawley & 2.785 & 48.026 & 15 & 776.000 & 0 & 0.481 \\
Roy's Greatest Root & 2.082 & 109.077 & 5 & 262.000 & 0 & 0.675 \\
\hline
\end{tabular}

$* P<0.05$,下同.

表 3 采样点空间多元方差分析

Tab.3 Spatial variation of sampling sites based on One-way multivariate analysis

\begin{tabular}{lcccccc}
\hline 统计量 & Value & F Value & Num DF & Den DF & Sig. & Partial Eta sq. \\
\hline Pillai's Trace & 1.545 & 1.355 & 330 & 1000.000 & 0 & 0.309 \\
Wilks' Lambda & 0.115 & 1.617 & 330 & 983.348 & 0 & 0.351 \\
Hotelling-Lawley & 3.385 & 1.994 & 330 & 972.000 & 0 & 0.404 \\
Roy's Greatest Root & 2.210 & 6.695 & 66 & 200.000 & 0 & 0.688 \\
\hline
\end{tabular}



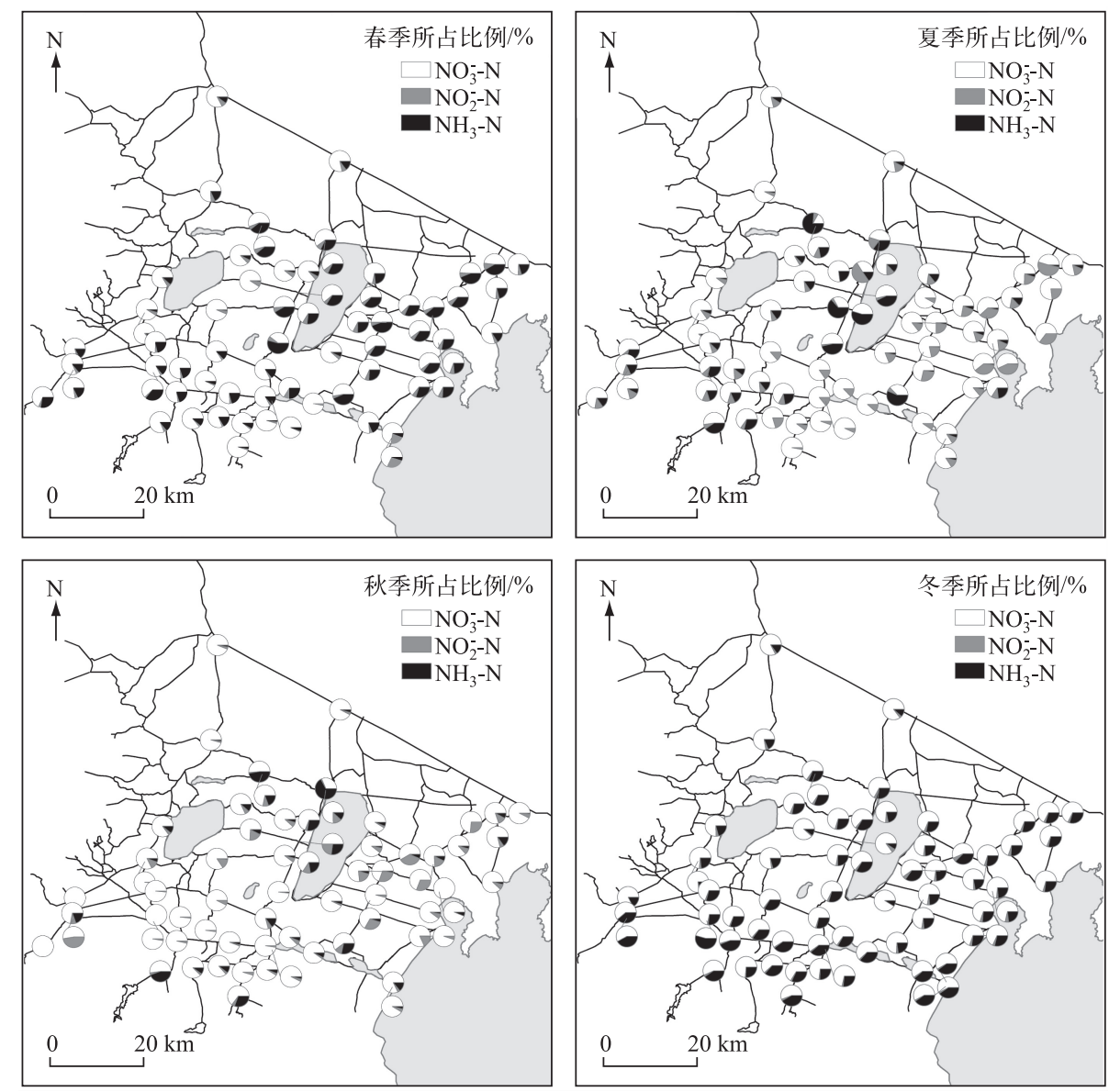

图 3 宜溧一洮滆水系各形态氮占无机氮比例的时空分布

Fig.3 The spatio-temporal distributions of percentages of different forms nitrogen to inorganic nitrogen in the Yili-Taoge river networks

分析中 Wilks' Lambda 为例, $P($ Sig. $=0.000)<0.05$, 说明不同季节内监测数据差异显著, 偏 Eta 方值为 0.430 , 说明可以解释变异的 $43.0 \%$. 结果显示 4 种不同统计量在时间尺度及空间尺度上 $P($ Sig. $=0.000)$ 值均小于 0.05 , 因此在变量 $\mathrm{DO} 、 \mathrm{COD}_{\mathrm{Mn}} 、 \mathrm{NH}_{3}-\mathrm{N} 、 \mathrm{TN}$ 和 $\mathrm{TP}$ 的联合分布下, 不同监测断面在不同季节内均存在显著差异.

\section{3 聚类分析结果}

针对耗氧污染物类指标 (DO、COD $\mathrm{Mn}_{\mathrm{Mn}} 、 \mathrm{NH}_{3}-\mathrm{N}$ ) 和营养盐类指标 $(\mathrm{TN} 、 \mathrm{TP})$, 利用 Ward 法对各监测点进行 聚类分析, 结果如表 4 和图 4 所示. 耗氧污染物类指标分为 3 组, 其中, $\mathrm{A} 1$ 样本量为 12 个, 主要聚集了 $\mathrm{COD}_{\mathrm{Mn}}$ 较高样本点, 主要分布在溧阳市的部分宜溧水系、埝径河及部分人湖河口附近; $\mathrm{A} 2$ 聚集了较高 $\mathrm{DO}$ 、同 时 $\mathrm{NH}_{3}-\mathrm{N}$ 浓度较低的样本点, 主要分布在流域上游的金坛市及丹阳市内, 即流域污染较小的区域; $\mathrm{A} 3$ 聚集 了 $\mathrm{NH}_{3}-\mathrm{N}$ 浓度较高的样本点, 其个数占所有样本点的 $60 \%$ 左右, 表明流域内 $\mathrm{NH}_{3}-\mathrm{N}$ 污染较为严重, 空间分 布主要在城市、工业化较为集中的区域.

营养盐类指标 $(\mathrm{TN} 、 \mathrm{TP})$ 分为 3 组, 污染程度顺序为 $\mathrm{B} 1<\mathrm{B} 2<\mathrm{B} 3$. 其中 $\mathrm{B} 1$ 组氮、磷污染程度最低, 样本个 数最多, 主要分布在洮湖和滆湖之间农业土地利用为主的区域, 集中于北干河、中干河、湟里河、宜溧水系中 河主干及其主要支流水系; B2 组氮、磷污染程度较 B1 略高, 主要位于丹金溧漕河、扁担河一孟津河、宜溧水 系南河主干; B3 组氮、磷污染最为严重, 同时样本个数相对较多, 且分布最为集中, 主要位于武进区, 锡溧漕 河一武宜运河、太滆运河、殷村港、漕桥河、夏溪河等沿线河流. 
表 4 不同聚类组水质指标均值

Tab.4 Average values of water quality index in different groups from cluster analysis

\begin{tabular}{ccccccccccc}
\hline & 组别 & $\begin{array}{c}\text { 样本 } \\
\text { 个数 }\end{array}$ & $\begin{array}{c}\mathrm{DO} / \\
(\mathrm{mg} / \mathrm{L})\end{array}$ & $\begin{array}{c}\mathrm{COD}_{\mathrm{Mn}} / \\
(\mathrm{mg} / \mathrm{L})\end{array}$ & $\begin{array}{c}\mathrm{NH}_{3}-\mathrm{N} / \\
(\mathrm{mg} / \mathrm{L})\end{array}$ & 组别 & $\begin{array}{c}\text { 样本 } \\
\text { 个数 }\end{array}$ & $\begin{array}{c}\mathrm{TN} / \\
(\mathrm{mg} / \mathrm{L})\end{array}$ & $\begin{array}{c}\mathrm{TP} / \\
(\mathrm{mg} / \mathrm{L})\end{array}$ \\
\hline 耗氧污染 & $\mathrm{A} 1$ & 12 & $5.84 \pm 0.55$ & $10.01 \pm 0.64$ & $0.49 \pm 0.12$ & 营养盐 & $\mathrm{B} 1$ & 26 & $4.05 \pm 0.73$ & $0.17 \pm 0.04$ \\
物类指标 & $\mathrm{A} 2$ & 12 & $6.70 \pm 0.35$ & $7.04 \pm 0.74$ & $0.28 \pm 0.08$ & 类指标 & $\mathrm{B} 2$ & 18 & $4.48 \pm 0.52$ & $0.28 \pm 0.03$ \\
& $\mathrm{~A} 3$ & 43 & $5.43 \pm 0.73$ & $7.13 \pm 1.05$ & $0.72 \pm 0.20$ & & $\mathrm{~B} 3$ & 23 & $6.28 \pm 0.43$ & $0.35 \pm 0.08$ \\
\hline
\end{tabular}
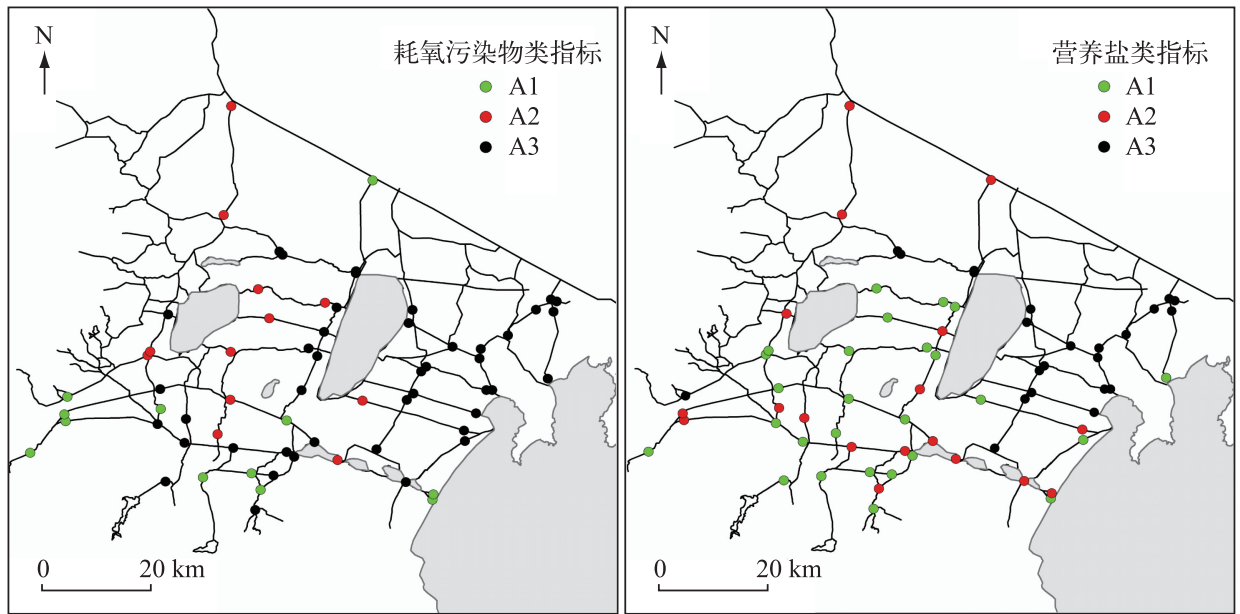

图 4 宜溧一洮滆水系不同水质指标聚类分析结果

Fig.4 The results of cluster analysis of different water-quality indexs in the Yili-Taoge river networks

\section{4 水质评价与特征污染物分析}

利用综合水质标识指数法对宜溧一洮滆水系监测期间内水质状况进行评价, 结果显示春季除极个别站 点达到 II 类或III类水标准,其余各站点均为 $\mathrm{I}$ 类或 $\mathrm{V}$ 类, 其中 $\mathrm{V}$ 类水主要分布在流域下游的太滆运河、漕桥 河、殷村港、锡溧漕河及直湖港; 夏、秋季水质状况有所改善, 仅少数站点为 $\mathrm{V}$ 类水, 其余大部分监测站点水 质类别为 $\mathrm{IV}$ 类, 部分达到 III 类, 空间差异性较小; 冬季水质状况较其他 3 季明显恶化, 仅少量站点为 IV 类, 其 余站点均为 $\mathrm{V}$ 类 (图 5). 根据不同季节综合水质标识指数均值可以看出, 流域内水质以 $\mathrm{I}$ 类及 $\mathrm{V}$ 类为主.

不同季节 DO、 $\mathrm{COD}_{\mathrm{Mn}} 、 \mathrm{NH}_{3}-\mathrm{N} 、 \mathrm{TN}$ 及 TP 各指标单因子水质标识指数均值分布情况 (图 6), DO 及 $\mathrm{NH}_{3}-\mathrm{N}$ 指数值相对较低, 以 II 类、 III 类水质为主; 而 $\mathrm{COD}_{\mathrm{Mn}} \mathrm{TN}$ 及 $\mathrm{TP}$ 的指数值明显偏高, 其中 $\mathrm{TN}$ 指数均值在不同 季节均超过 5.0 , 总体处于 $\mathrm{V}$ 类水质标准以上. 耗氧污染类指标中, $\mathrm{COD}_{\mathrm{Mn}}$ 平均超过 $\mathrm{IV}$ 类标准, 为主控指标; 营 养盐指标则需要对 TP 和 TN 进行控制, 其中 TN 控制是改善平原河网区整体水质的关键所在.

\section{3 讨论}

监测和分析结果表明, 2015 年宜溧一洮滆水系水质主要以 $\mathrm{I}$ 类及 $\mathrm{V}$ 类为主, $\mathrm{COD}_{\mathrm{Mn}}$ 、 $\mathrm{TN}$ 、 $\mathrm{TP}$ 浓度均值分 别为 7.63、4.93、0.26 mg/L, 其中氮污染最为严重, 这与太湖流域各类化肥中氮肥施用量最大, 且作物对氮吸 收率较低有关 ${ }^{[26]}$. 与 2008- 2010 年水质相比 ${ }^{[27-28]}$, 宜溧一洮滆水系 TN 、TP 的浓度均不同程度有所上升, 分 析认为人湖河流水质受农业面源与工业点源污染的双重影响, 近年来太湖流域污染治理虽逐渐加强, 但较 多集中于工业点源污染, 同时以种植生态公益林为主的面源污染治理建设时间尚短, 林分结构和森林功能 仍不健全与完善, 对水质的改善作用尚不显著. 随着对工业点源污染治理的加强, 面源污染负荷比例逐渐增 加, 养殖废水、生活污水等不合理排放以及农业径流等因素均对水质产生一定影响 ${ }^{[29-31]}$, 导致宜溧一洮滆水 

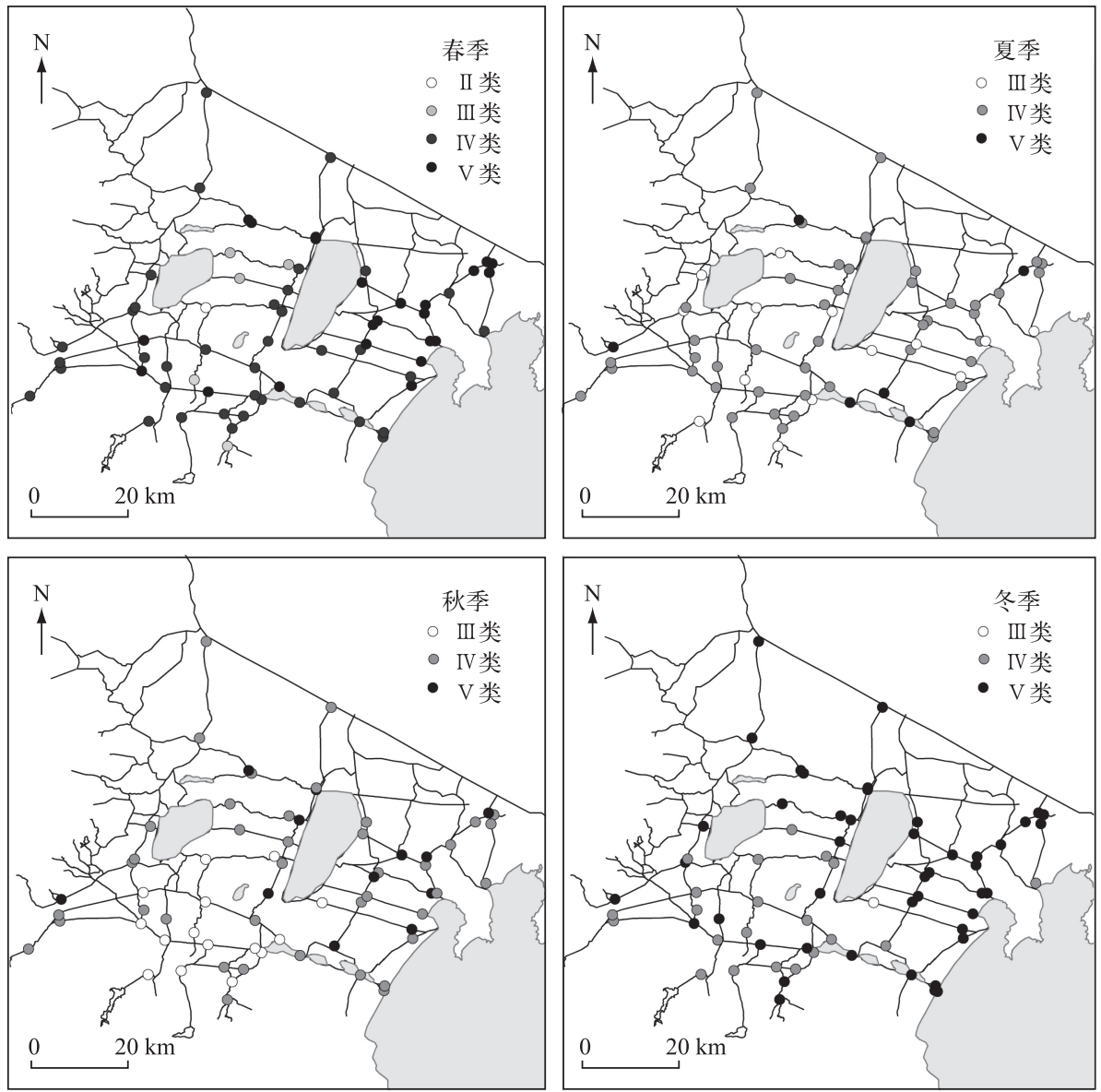

图 5 宜溧一洮滆水系综合水质标识指数评价结果时空分布

Fig.5 The spatio-temporal distributions of assessment result class using comprehensive water quality identification index in the Yili-Taoge river networks

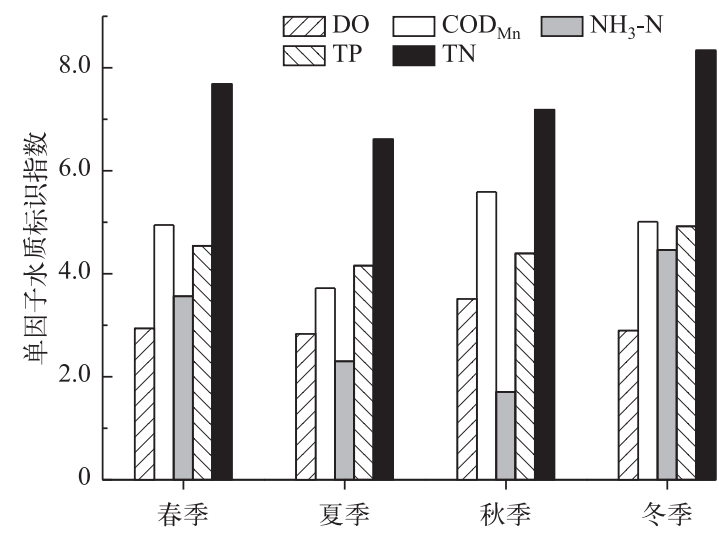

图 6 宜溧一洮滆水系单因子水质标识指数季节分布

Fig.6 Seasonal distribution of single-factor water identification index in the Yili-Taoge river networks 
系水质氮污染有所加剧, 同时河流改道、河岸带植被衰减、建设区开发等人为干扰对河网水体连通性造成一 定影响, 导致不同水体间的交换能力下降, 因此水体水质恢复相对较慢 ${ }^{[32]}$. 此外, 不同形态的 DTN 为 TN 的 主要组成成分,所占比例均值为 $59.59 \%$, 尽管 DTN 的 3 种形态在不同季节不同监测点所占比例有显著差 异, 但仍以 $\mathrm{NO}_{3}^{-}-\mathrm{N}$ 为主要存在形态, 与许海等 ${ }^{[33]}$ 的研究结果一致, 分析认为与宜溧一洮滆水系频繁的船运 扰动有关, 水体在剧烈扰动下复氧能力及硝化作用均有所增强, 从而导致 $\mathrm{NO}_{3}^{-}-\mathrm{N}$ 浓度偏高 ${ }^{[34]}$.

从季节变化来看, 在 2015 年宜溧一洮滆水系污染程度整体呈现冬、春季较高, 夏、秋季较低的特征. 不 同季节水质变化主要受其温度、降水、水文条件等影响 ${ }^{[35-36]}$, 在冬、春两季宜溧一洮滆水系污染较为严重, 其 中在冬季水质指标 $\mathrm{COD}_{\mathrm{Mn}} 、 \mathrm{TN} 、 \mathrm{TP}$ 浓度均值分别达到 $8.78 、 6.89 、 0.31 \mathrm{mg} / \mathrm{L}$, 基本处于 $\mathrm{V}$ 类或劣 $\mathrm{V}$ 类水质标 准, 春季污染物浓度较冬季有所降低, 但仍然处于高值范围, 一方面冬、春两季降雨量小导致河流水位下降, 稀释净化能力相对降低, 另一方面冬季微生物活动的减弱, 使得流域内污水处理厂污染物处理效率降低, 同 时河流自净能力减弱也是污染物浓度高的重要原因. 与此相反, 夏、秋两季丰水期对河流氮、磷污染物浓度 产生了较强的稀释作用, 同时水温增加, 流域及河道内微生物作用的增强, 能够降低水体营养盐浓度.

宜溧一洮滆水系水质污染程度在空间上大体呈现北高南低、东高西低的分布特征, 同时利用层次聚类 的方法能够很好表征水质指标的空间分布规律. 流域内两类指标均聚成 3 类, 具有显著的空间差异性,同时 营养盐类指标与耗氧污染物类指标空间分布具有一定相似性. 位于流域下游的锡溧漕河一武宜运河、太滆 运河以及殷村港、漕桥河等人湖河口附近样本点营养盐类指标及 $\mathrm{NH}_{3}-\mathrm{N}$ 污染均最为严重, 这些河流主要位 于太湖流域城镇化和工业化高度集中的区域 (即无锡、常州以及宜兴市的交汇区域), 体现了强烈的人为活 动影响. 土地利用是影响污染物排放量的重要因素 ${ }^{[17]}$, 其一方面通过不同人类活动方式和强度影响营养盐 的输人量, 另一方面则通过改变地表粮率影响地表径流过程. 已有研究表明, 林地面积的增加对水质改善发 挥积极作用, 而农田和城镇用地面积的增加则使水质趋于恶化 ${ }^{[32]}$. 近些年, 太湖流域土地利用情况发生明 显改变,与 2000 年相比, 2008 年农田占地率从 $60 \%$ 下降至 $51 \%$, 城镇用地则由 $13 \%$ 上升至 $22 \%{ }^{[15]}$. 其中无 锡、常州市的土地利用类型均以城镇用地及耕地为主, 林地、水域所占比例均较低, 区域内人口居住密度大, 因此认为大量的工业点源污染排放、生活污水排放及不完善的污水处理系统是造成该区域附近水域氮、磷 污染严重的主要原因 ${ }^{[37]}$. 同时由于受河流流向影响, 污染物在人湖河口附近呈逐渐累积现象, 从而导致流 域下游区域污染物浓度偏高. 此外, 距离监测点最近的土地利用类型对水质的影响较区域综合土地利用情 况对水质的影响更大 ${ }^{[38]}$, 由于污染严重区域主要集中于人湖河口附近, 流量大且污染物衰减距离短, 也可能 是限制太湖水质提高的重要因素.

综合水质指数标识法能够较为客观地反映河流的综合水质类别、与水功能区类别的比较结果等信 息 ${ }^{[39]}$. 评价结果表明宜溧一洮滆水系主要以 $I I I \sim V$ 类水质为主, 总体能够满足区域水体功能目标. 单因子水 质标识指数结果表明, TN、TP、 $\mathrm{COD}_{\mathrm{Mn}}$ 为目前宜溧一洮滆水系特征污染物, 以氮为主要控制指标, 与余辉 等 ${ }^{[28]}$ 研究结果一致, 因此控氮是提高研究区域水环境质量的关键所在. 同时, 从太湖湖泊生态系统来看, 氮 的控制也具有重要意义. 传统观点认为磷是湖泊水体生产力的主要限制因子, 我国自 1998 年颁布对太湖禁 磷政策以来, 磷污染程度有所下降,对太湖富营养化进一步恶化起到延缓的作用,但近些年的研究表明太湖 藻类生长受到氮、磷的共同限制 ${ }^{[40-43]}$, 夏、秋季以氮限制为主, 冬、春季以磷限制为主. 从流域输人上可以看 出, 夏、秋季营养盐浓度较低而冬、春季较高, 而湖泊水体中夏、秋季内源磷负荷较大, 加上氮的反硝化作用, 使得水体受到氮限制, 因此氮外源输人控制对减轻太湖蓝藻水华具有重要的意义.

\section{4 结论}

1) 综合指数标识评价结果表明宜溧一洮滆水系以 $I V$ 类及 $V$ 类水质为主, 各监测点 DIN 为 TN 的主要组 成成分, 4 个季节均值比例范围为 $45.85 \% \sim 66.91 \%$. 在 DIN 的 3 种形态中, $\mathrm{NO}_{3}^{-}-\mathrm{N}$ 为主要存在形态, 所占比 例均值为 $74.41 \%$, 同时 $\mathrm{NH}_{3}-\mathrm{N}$ 浓度及比例分布能够很好地指示河流的氮污染程度.

2)基于营养盐和耗氧污染物两类指标, 利用单因素多元方差分析和聚类分析结果表明,宜溧一洮滆水 系不同水质指标浓度均具有显著的时空差异性. 季节上主要受温度、降雨量等因素影响, 水系污染程度总体 呈现冬、春季较高,夏、秋季较低特征; 空间上污染程度大体呈现北高南低、东高西低的分布特征, 且空间聚 
集规律明显;受土地利用类型和地理位置影响,无锡、常州、宜兴交汇区域为氮、磷污染最为严重区域,也是 污染控制的关键区.

\section{5 参考文献}

[ 1 ] Fan Ronggui, Zhu Dongnan, Deng Lan. Causes of eutrophication and progress of integrated management technology in lake. Journal of Water Resources \& Water Engineering, 2010, 21(6) : 48-52. [范荣桂, 朱东南, 邓岗. 湖泊富营养化 成因及其综合治理技术进展. 水资源与水工程学报, 2010, 21(6) : 48-52.]

[ 2 ] Xu Qigong, Cao Jinling, Gao Rutai et al. Trend of water quality deterioration and eutrophication control phases partition in China. Environmental Science \& Technology, 2011, 34(11): 147-151. [许其功, 曹金玲, 高如泰等. 我国湖泊水质恶 化趋势及富营养化控制阶段划分. 环境科学与技术, 2011, 34(11)：147-151.]

[ 3 ] Wu Yali, Xu Hai, Yang Guijun et al. Progress in nitrogen pollution research in Lake Taihu. J Lake Sci, 2014, 26(1): 19-28. DOI: 10.18307/2014.0103. [ 吴雅丽, 许海, 杨桂军等. 太湖水体氮素污染状况研究进展. 湖泊科学, 2014, 26(1): 19-28.]

[ 4 ] Xu Hai, Qin Boqiang, Zhu Guangwei. Nutrient limitation of cyanobacterial growth in different regions of Lake Taihu in summer. China Environmental Science, 2012, 32(12): 2230-2236. [许海, 秦伯强, 朱广伟. 太湖不同湖区夏季蓝藻 生长的营养盐限制研究. 中国环境科学, 2012, 32(12): 2230-2236. ]

[ 5 ] Wang Wei. Study and application digital simulation on river water quality management by computational intelligence [ Dissertation]. Harbin: Harbin Institute of Technology, 2013. [王神. 基于计算智能方法的河流水质管理数字模拟研究与 应用 [学位论文]. 哈尔滨: 哈尔滨工业大学, 2013.]

[ 6 ] Zhao Tingting, Li Qiuyan, Lu Liqiao et al. Analysis of water environmental pollution in plain river network region in smallwatershed of Caoqiao River. Transactions of the CSAE, 2011, 27(Supp.2) : 170-175. [ 赵婷婷, 李秋艳, 陆丽巧等. 漕 桥河小流域平原河网地区水环境污染分析. 农业工程学报, 2011, 27(S2)：170-175.]

[ 7 ] Pan Hongbo. Lake eutrophication and its prevention measures. Environmental Science and Technology, 2011, 24(S1): 123-126. [潘红波. 湖泊富营养化问题及其防治浅议. 环境科技, 2011，24(S1)：123-126. ]

[ 8 ] Xu Mei, Ren Ruili, Liu Maosong. Annual changes of water quality in an upstream river of Taihu Lake. Journal of Nanjing Forestry University: Natural Sciences Edition, 2007, 31(6): 121-124. [许梅, 任瑞丽, 刘茂松. 太湖人湖河流水质指标 的年变化规律. 南京林业大学学报: 自然科学版, 2007, 31(6): 121-124.]

[ 9 ] Jing Hongwei, Zhang Zhigang, Guo Jing. Water pollution characteristics and pollution sources of Bei Canal river system in Beijing. China. Environmental Science, 2013, 33(2): 319-327. [ 荆红卫, 张志刚, 郭婧. 北京北运河水系水质污染特 征及污染来源分析. 中国环境科学, 2013, 33(2): 319-327.]

[10] Wang XZ, Cai QH, Ye L et al. Evaluation of spatial and temporal variation in stream water quality by multivariate statistical techniques: A case study of the Xiangxi River basin, China. Quaternary International, 2012, 282(2) : 137-144.

[11] Wang Gang, Li Zhaofu, Wan Rongrong et al. Analysis of temporal and spatial variations in water quality of Xitiaoxi Watershed using multivariate statistical techniques. Journal of Agro-Environment Science, 2015, 34(9): 1797-1803. [王刚, 李 兆富, 万荣荣等. 基于多元统计分析方法的西苦溪流域水质时空变化研究. 农业环境科学学报, 2015, 34(9): 1797-1803.]

[12] Xu Huashan, Xu Zongxue, Tang Fangfang et al. Spatio-temporal variation analysis and identification of water pollution sources in the Zhangweinan River Basin. Environmental Science, 2012, 33(2): 359-369. [徐华山, 徐宗学, 唐芳芳等. 漳卫南运河流域水质时空变化特征及其污染源识别. 环境科学, 2012, 33(2) : 359-369.]

[13] Xie Ying, Li Xuyong, Wang Huiliang et al. Stream pollution analysis and hydro-chemical assessment of the upper Luanhe River Basin. Acta Scientiae Circumstantiae, 2012, 32(3): 645-653. [解芗, 李叙勇, 王慧亮等. 滦河流域上游地区主 要河流水污染特征及评价. 环境科学学报, 2012, 32(3): 645-653.]

[14] Li YP, Acharya K, Stone MC et al. Spatio-temporal patterns in nutrient loads, nutrient concentrations, and algal biomass in Lake Taihu, China. Lake and Reservoir Management, 2011, 27(4) : 298-309.

[15] Xu H, Yang LZ, Zhao GM et al. Anthropogenic impact on surface water quality in Taihu lake region, China. Pedosphere, 2009, 19(6): 765-778.

[16] Lu Shaoyong, Jiao Wei, Wang Qiang et al. Spatial-temporal distribution characteristics of water quality of rivers around 
Taihu Lake. Research of Environmental Sciences, 2011, 24(11)：1220-1225. [卢少勇, 焦伟, 王强等. 环太湖河流水 质时空分布特征. 环境科学研究, 2011, 24(11): 1220-1225.]

[17] Niu Yong, Yu Hui, Zhang Min et al. Impact of land-using pattern on water quality of rivers in Lake Taihu watershed. Resources and Environment in the Yangtze Basin, 2013, 22(2): 205-211. [牛勇, 余辉, 张敏等. 太湖流域典型土地利用 方式下人湖河流水质污染特征研究. 长江流域资源与环境, 2013, 22(2) : 205-211.]

[18] Shi Yunxiang. Water environment evolution tends and the pollutant transport process research of Yili River [Dissertation]. Nanjing: Nanjing University of Science and Technology, 2002. [史云祥. 宜溧河流域水环境演变趋势以及污染物输移 过程研究 [学位论文]. 南京: 南京理工大学, 2002.]

[19] Gu Xiejun, Xu Dongtong, Cai Huanxing et al. Feature analysis and comparison on ecological risk of eutrophication in lakes and reservoirin Taoge River. Environmental Monitoring and Forewarning, 2011, 3(3): 13-17. [顾谢军, 徐东昫, 蔡焕 兴等. 洮滆水系湖库富营养化生态风险的特点与比较. 环境监控与预警, 2011, 3(3): 13-17.]

[20] Zhang Yiming, Zhang Yongchun, Gao Yuexiang et al. Water pollution control technology and strategy for pollution control of water body of River-Lake System. Journal of Ecology and Rural Environment, 2010, 26(S1): 9-13. [张毅敏, 张永 春, 高月香等. 河湖相连水系水体污染控制技术与策略. 生态与农村环境学报, 2010, 26( S1) : 9-13.]

[21] Ministry of Environmental Protection of the People's Republic of China, Editorial Board of Water and Wastewater Monitoring and Analysis Methods eds. Water and Wastewater Monitoring and Analysis Methods: 4th edition. Beijing: China Environmental Science Press, 2002. [ 国家环境保护总局《水和废水监测分析方法》编委会. 水和废水监测分析方法:第 4 版. 北京: 中国环境科学出版社, 2002.]

[22] Fu Tianyi, Zou Zhihong, Wang Xiaojing. Water quality assessment for Taizi River watershed in Liaoyang section based on multivariate statistical analysis and water quality identification index. Acta Scientiae Circumstantiae, 2014, 34(2): 473480. [富天乙, 邹志红, 王晓静. 基于多元统计和水质标识指数的辽阳太子河水质评价研究. 环境科学学报, $2014,34(2): 473-480$. ]

[23] Harrington PB, Vieira NF, Espinoza J et al. Analysis of variance-principal component analysis: A soft tool for proteomic discovery. Analytica Chimica Acta, 2005, 544(1) : 118-127.

[24] Tang Linan, Liu Yu, Pan Yuchun et al. Evaluation and zoning of rural regional multi-function based on BP model and Ward method: A case in the Pinggu district of Beijing city. Scientia Geographica, 2016, 36(10) : 1514-1521. [唐林楠, 刘玉, 潘瑜春等. 基于 BP 模型和 Ward 法的北京市平谷区乡村地域功能评价与分区. 地理科学, 2016, 36(10): 1514-1521.]

[25] Xu Zuxin. Comprehensive water quality identification index for environmental quality assessment of surface water. Journal of Tongji University: Natural Science, 2005, 33(4): 482-488. [徐祖信. 我国河流综合水质标识指数评价方法研究. 同济大学学报: 自然科学版, 2005, 33(4): 482-488.]

[26] Cheng Bo, Zhang Ze, Chen Ling et al. Eutrophication of Taihu Lake and pollution from agricultural non-point sources in Lake Taihu Basin. Journal of Agro-Environment Science, 2005, 24(S1): 118-124. [程波, 张泽, 陈凌等. 太湖水体富 营养化与流域农业面源污染的控制. 农业环境科学学报, 2005, 24(S1) : 118-124.]

[27] Wang Xue, Xu Hui, Yan Shuwen et al. Spatial distribution characteristics of up-stream river pollution in lakeTaihu basin. Resources and Environment in the Yangtze Basin, 2012, 21(3): 341-348. [王雪, 余辉, 燕姝雯等. 太湖流域上游河流 污染空间分布特征研究. 长江流域资源与环境, 2012, 21(3) : 341-348.]

[28] Yu Hui, Yan Shuwen, Xu Jun. Multivariate statistical analysis of water quality in the inflow and outflow rivers of Lake Taihu. Resources and Environment in the Yangtze Basin, 2010, 19(6): 696-702. [余辉, 燕姝雯, 徐军. 太湖出人湖河 流水质多元统计分析. 长江流域资源与环境, 2010, 19(6): 696-702.]

[29] Jarvie HP, Whitton BA, Neal C. Nitrogen and phosphorus in east-coast British rivers: speciation, sources and biological significance. Science of the Total Environment, 1998, S210-211(1-6) : 79-109.

[30 ] Ravichandran S. Hydrological influences on the water quality trends in Tamiraparani Basin, south India. Environmental Monitoring and Assessment, 2003, 87(3) : 293-309.

[31] Xian G, Crane M, Junshan S. Analysis of urban development and its environmental impact on the Tampa Bay watershed. Journal of Environmental Management, 2007, 85(4) : 965-976.

[32] Hu Jian, Liu Maosong, Zhou Wen et al. Correlations between water quality and land use pattern in Taihu Lake basin. Chinese Journal of Ecological, 2011, 30(6): 1190-1197. [胡建, 刘茂松, 周文等. 太湖流域水质状况与土地利用格局 
的相关性. 生态学杂志, 2011, 30(6): 1190-1197.]

[33] Xu Hai, Liu Zhaopu, Jiao Jiaguo et al. Nitrogen pollution status of various types of passing-by water bodies in upper reaches of Taihu Lake. Chinese Journal of Ecological, 2008, 27(1): 43-49. [许海, 刘兆普, 焦佳国等. 太湖上游不同类 型过境水氮素污染状况. 生态学杂志, 2008, 27(1): 43-49.]

[34] Liu Yun, Yi Qitao, Chen Qiuwen et al. The spatial distribution of nitrogen species in surface sediment in the west river networks of the Taihu Lake Basin, China. Acta Scientiae Circumstantiae, 2015, 35(12): 3890-3897. [刘芸, 易齐涛, 陈求稳等. 太湖西部河网中沉积物氮的空间分布特征. 环境科学学报, 2015, 35(12): 3890-3897.]

[35] Vega M, Pardo R, Barrado E et al. Assessment of seasonal and polluting effects on the quality of river water by exploratory data analysis. Water Research, 1998, 32(12) : 3581-3592.

[36] Ouyang Y, Nkedi-kizza P, Wu QT et al. Assessment of seasonal variations in surface water quality. Water Research, 2006, 40(20) : 3800-3810.

[37] Xu Pengzhu, Qin Boqiang, Huang Wenyu et al. Assessment of water quality and nutrition to water bodies the Yilihe Watershed, Taihu Basin. J Lake Sci, 2001, 13(4) : 315-321. DOI: 10.18307/2001.0405. [许朋柱, 秦伯强, 黄文钜等. 太 湖流域宜溧河地区水体水质状况及营养状态评价. 湖泊科学, 2001, 13(4): 315-321.]

[ 38 ] Cao Fangfang, Li Xue, Wang Dong. Effects of land use structure on water quality in Xin'anjiang River. Environmental Science, 2013, 34(7) : 2582-2587. [曹芳芳, 李雪, 王东. 新安江流域土地利用结构对水质的影响. 环境科学, 2013, 34 $(7): 2582-2587$.

[39] Xie Ying, Li Xuyong, Wang Huiliang et al. Stream pollution analysis and hydro-chemical assessment of the upper Luanhe River Basin. Acta Scientiae Circumstantiae, 2012, 32(3): 645-653. [解莹, 李叙勇, 王慧亮等. 滦河流域上游地区主 要河流水污染特征及评价. 环境科学学报, 2012, 32(3): 645-653.]

[40] Paerl HW, Hall NS, Calandrino ES. Controlling harmful cyanobacterial blooms in a world experiencing anthropogenic and climatic-induced change. Science of the Total Environment, 2011, 409(10) : 1739-1745.

[41] Paerl HW, Xu H, Hall NS. Nutrient limitation dynamics examined on a multiannual scale in Lake Taihu, China: implications for controlling eutrophication and harmful algal blooms. Freshwater Ecology, 2015, 30(1) : 5-24.

[42] Paerl HW, Xu H, McCarthy MJ et al. Controlling harmful cyanobacterial blooms in a hyper-eutrophic lake ( Lake Taihu, China): The need for a dual nutrient ( N \& P) management strategy. Water Resource, 2011, 45( 5) : 1973-1983.

[43] Ma JR, Qin BQ, Wu P et al. Controlling cyanobacterial blooms by managing nutrient ratio and limitation in a large hypereutrophic lake: Lake Taihu, China. Journal of Environment Science, 2015, 27(1) : 80-86. 